\title{
The rise of phosphorus recycling facilitated Earth's Great Oxidation
}

\author{
LEWIS J ALCOTT ${ }^{1}$, BENJAMIN J. W. MILLS ${ }^{2}$, ANDREY \\ BEKKER $^{3}$ AND SIMON W. POULTON ${ }^{2}$ \\ ${ }^{1}$ Yale University \\ ${ }^{2}$ School of Earth and Environment, University of Leeds \\ ${ }^{3}$ University of California \\ Presenting Author: lewis.alcott@yale.edu
}

The rise of atmospheric oxygen during the Great Oxidation Event (GOE) $\sim 2.4$ billion years ago was a defining transition in the evolution of global biogeochemical cycles and life on Earth. There is, however, abundant evidence for mild oxidative continental weathering and the development of ocean oxygen oases several hundred million years prior to the GOE. The GOE thus represents a threshold, whereby primary productivity and $\mathrm{O}_{2}$ production overwhelmed the input of reduced species that consume $\mathrm{O}_{2}$, and its timing is assumed to be related to a balance between the riverine input of the major limiting nutrient, phosphate, and the dynamics of the solid Earth. However, the sequence of events that ultimately facilitated persistent atmospheric oxygenation remains elusive.

Here, we report novel geochemical analyses of $\sim 2.65$ to 2.43 Ga drill core samples from the Transvaal Supergroup, South Africa. Phosphorus speciation demonstrates that under dominant ferruginous conditions, indicative of the Archean, phosphorus is efficiently sequestered within the sediment. However, intervals that demonstrate intense sulfide production, which themselves were a progressive response to the onset of oxidative continental weathering, display phosphorus recycling, proposing enhanced availability of phosphorus in the run up to the GOE.

Biogeochemical modelling of the global implications for primary productivity shows that the evolution of phosphorus recycling was the critical step that enabled Earth's transition to a persistently oxygenated atmosphere. 